Vol. 4, Issue 1, July 2021

\title{
High School Students' Learning During the COVID-19 Pandemic: Perspectives from Health Sciences and Technology Academy Participants
}

\author{
Sherron Benson McKendall, PhD'; Alan McKendall, PhD²; Ann Chester, PhD'; Catherine Morton, EdD'; \\ Sean Freeland, MA'; Summer Kuhn, MPH$^{1}$; and Mary McMillion, MA $^{1}$
}

${ }^{1}$ Health Sciences and Technology Academy and ${ }^{2}$ Department of Industrial and Management Systems Engineering, West Virginia University, Morgantown, WV Keywords: Learning Environments during COVID, student perspectives on learning amidst the COVID pandemic, Health Sciences and Technology Academy (HSTA), high school, out-of-school-time programs, underrepresented, first generation, financially disadvantaged, rural, chi-square analyses

Publication Date: July 19. 2021

DOI: https://doi.org/10.15695/jstem/v4i2.09

\begin{abstract}
This paper examines the perspectives of Health Sciences and Technology Academy (HSTA) participants as they navigate through their West Virginia (WV) high school learning environments (i.e., in-person, blended/hybrid, complete virtual) during the novel coronavirus, SARS-CoV-19 (COVID-19) pandemic. In March of 2020, the participants in this out-of-school-time (OST) academic enrichment program for exceptionally driven, yet underprivileged, at-risk students, with over $70 \%$ living in rural areas, started receiving remote learning instruction through learning management systems or via paper packets. In August of 2020, school systems provided parents and caregivers alternative learning environments for their student(s). In order to understand the learning experiences of HSTA students during these unprecedented times, HSTA released the 2020 Learning Outcomes Survey to participants in December of 2020. We performed chi-square test of independence to test the relationship between participants' learning environments, their satisfaction with the education they were receiving, their ability to keep up with their school-work, teacher availability to help when needed and teacher feedback supporting them in their learning environment. The results show significant differences between the learning environments and keeping up with school-work as well as teacher feedback supporting them in their learning; however, Phi and Cramer's $\mathrm{V}$ tests for effect size show weak correlations. This study provides a small glimpse into HSTA students' learning experiences as they attempted to continue to learn in their regular school environment during the COVID-19 pandemic while in HSTA.
\end{abstract}

\section{INTRODUCTION}

In March of 2020, global pandemonium occurred shaking multifaceted systems to the core by an international pandemic. In the midst of this pandemic, educational leaders at every facet in the system (i.e., parents, teachers, principals, school boards, state and federal departments of education, governors, etc.) encountered the daunting task of developing alternative systems to replace in-person learning. There are differing opinions and studies regarding the effectiveness of on-line versus in-person learning in adequately preparing the next generation of leaders (Arias, Swinton, and Anderson, 2018; Means et al., 2009; Paul and Jefferson, 2019; Oppenheimer, 2003). Nevertheless, educational entities worldwide had to develop alternative systems for instructional delivery to protect teachers and students from the threat of possibly contracting the novel coronavirus, SARS-CoV-19 (COVID-19) virus (Reimers et al., 2020; WVDE, 2021; WVDE, n.d.).

West Virginia's Reaction to COVID-19. On February 8, 2020, the West Virginia Department of Education (WVDE) Superintendent of Schools issued a memo recommending all 55 counties "review their emergency preparedness plans for infectious disease outbreaks" (WVDE, 2021). Four days later, Governor Jim Justice issued a State of Preparedness for West Virginia. Thus, on March 13, 2020, the Governor ordered that all West Virginia schools move to a remote 
learning platform. The West Virginia educational delivery platform "included online lessons, virtual teaching, paper packets, phone calls and other types of outreach to keep students engaged" (WVDE, 2021). Although this was the most realistic alternative under the circumstances, remote learning presented difficulties for students to remain engaged due to inconsistencies in the virtual and remote learning platforms. Additionally, some students were without technology resources (e.g., computers) in their homes. Other students lacked internet coverage due to the state's rural terrain. According to a 2019 Broadband report, WV ranked as the 7th and 2nd lowest in fixed wireline broadband access and mobile broadband access, respectively (Tilson and The West Virginia Broadband Enhancement Council, 2019). Other possible learning impediments are the lack of technologically informed caregivers or quiet study space and time in their homes leading to unequal access to quality education for certain WV student populations.

These challenges continued to persist with Governor Justice announcing on April 21, 2020 that WV schools would remain closed through the remainder of the 2019-20 academic year. On July 8, 2020 in collaboration with the Department of Health and Human Resources (DHHR), the WVDE released a preliminary school re-entry guide for the 2020-21 school year. The WVDE released a revised version on July 28, 2020 (WVDE, 2021). On September 5, 2020, the WVDE began posting school re-entry metrics and protocols. These metrics determined which schools could open for in-person instruction based on established safety protocols. The DHHR worked with the WVDE to create the protocols, which designated risk levels. For West Virginia students, the date for school re-entry was September 8, 2020. Governor Justice required all counties to submit re-entry plans to the WVDE by Friday, August 14, 2020. Counties offered "multiple options for instruction," allowing parents and guardians the flexibility to choose the desired option for their student (Office of Governor Jim Justice, 2020). As school districts reopened for in-person learning, outbreaks occurred state wide at varying rates. Governor Justice also established a color-coded metric system determining school re-openings with green and yellow counties hosting in-person learning. Schools in red and orange designated counties operated under the remote learning module (Office of Governor Jim Justice, 2020).

Various educational delivery platforms existed prior to and have been developed during the pandemic. The WVDE designated four distinct platforms: In-Person Learning; Blended/Hybrid Learning; Local Virtual Learning; and West Virginia Virtual Learning. The In-Person and West Virginia Virtual Learning options were always available to students. However, the Blended/Hybrid and Local Virtual Learning options were developed and made available during the pandemic. In-Person Learning placed "students in a school setting with teachers providing instruction 4 or 5 days per week when school is in session." The Blended/Hybrid system placed students "in a school setting for a portion of the school day or week" and "off-site for the remainder of the school day or week." Students experienced reduced days or hours of in-person instruction. Local Virtual learners "receive(d) instruction off-site via an online learning management system with synchronous (live) or asynchronous (delayed) instructional support" from teachers in their county. Last, the West Virginia Virtual learners received "instruction off-site via an online learning management system" which is "a self-paced environment supported by a certified teacher and county facilitator" (WVDE, n.d.; Office of Governor Jim Justice, 2020). When an outbreak occurred at the state or county level, the WVDE implemented the "Emergency Outbreak Option," Remote Learning for educational delivery to K-12 WV students. This temporary learning module allowed students to remain engaged with teachers from their local schools through an online learning management system. Schools provided paper packets/materials for offline learning. However, due to WV's rural backdrop, many students had difficulty accessing virtual learning modules, so in August 2020, Governor Justice announced that WV would provide internet access to all students via the Kids Connect initiative (WSAZ, 2020; Young, 2020). This program provided 1,000 hotspot locations across the state so that students could complete their school assignments (WV Kids Connect, 2020).

HSTA's Response to COVID-19. Just as the school systems, the Health Sciences and Technology Academy (HSTA) discontinued all in-person meetings and programming. However, HSTA did not implement a virtual program until July 2020. HSTA leadership and staff worked with collaborators (e.g., university faculty) to create virtual programs for both the Summer of 2020 and 2021 as well as the Fall 2020 and Spring 2021 academic year. Therefore, HSTA students have not experienced in-person meetings since March of 2020. We detail the process of restructuring the program from in-person to virtual delivery in a forthcoming manuscript (McKendall et al., 2021).

Similar to all WV students, the pandemic produced uncertainties about learning in HSTA participants. These high school underrepresented students are African American, first generation college attendees, financially disadvantaged and/ or rural who reside in 26 of the $55 \mathrm{WV}$ counties. Approximately, $43 \%$ are students of color, $70 \%$ are female, $61 \%$ are low income, and $68 \%$ are potential first-generation college attendees. These students have a unique voice and provide an important perspective to the conversation on equity and access to education. Comparison studies of HSTA students to non-HSTA populations have shown statistically significant differences favoring HSTA participants on standard- 
ized test scores (McKendall et al., 2019; Smith et al., 2018). Thus, they are self-motivated and have a desire to achieve. An overwhelming $99 \%$ of students completing the program attend college. In comparison, 56\% of WV high school graduates go to college. Approximately $85 \%$ of HSTA graduates attending college graduate with a four-year degree and $57 \%$ have received STEM degrees. Nationally, only $25.8 \%$ of college graduates received STEM Bachelor's degrees between 1995 and 2016 (Chester et al., 2020). HSTA students make a big commitment to their futures by joining this four-year program starting in the 9th grade. To remain in HSTA, the participants must maintain a 3.0 high school GPA as well as attend a minimum of $70 \%$ of their HSTA meetings and activities. HSTA students are also required to prepare and present a yearly science research project, attend at least two Summer Institutes over the course of the four years in the program as well as dedicate 75 hours of community service at a local hospital, church, school, etc. A final requirement for successful program completion is exhibiting above average behavior in school, which means not getting in trouble. Despite being an environmentally fragile and vulnerable population, HSTA students are intelligent and ambitious. In order to understand the psychological impacts on the learning of exceptionally driven but vulnerable students during the COVID-19 pandemic, we will examine HSTA participants' perspectives as they navigate through their WV high school learning environments (i.e., in-person, blended/hybrid, complete virtual).

Traditionally, underrepresented students have difficulties navigating educational systems. Historical documents such as the Coleman report provided detailed descriptions of the educational inequalities underprivileged students encounter (Coleman et al., 1966). High school disparities lead to college disparities as shown in The Condition of College and Career Readiness 2018 report released by ACT. As noted in this report, US students' college readiness is stagnant or possibly declining, with the exception of Asian students. Underserved students, especially those who meet all criteria (i.e., African American and other minority, financially disadvantaged, and first-generation college) consistently do not meet three or more benchmarks (i.e. English, Math, Reading, Science) for college readiness. These educational disparities will become more evident. As feared, estimates of learning loss due to the pandemic will have negative educational ramifications with lasting and devastating impact (Engzell et al., 2021; Hanushek and Woessmann, 2020). Compounded with the pre-existing educational disparities experienced by underrepresented youth, it is yet to be clearly determined the length of time it will take for underprivileged students to recover from COVID-19 learning disparities (Anderson and Perrin, 2018; Chen et al, 2021; Dorn et al, 2021; Perrin, 2019). More evidenced-based assessments to determine how deep the waters of COVID-19 learning loss run are needed
(Kuhfeld et al., 2020). Thus, the purpose of this study is to provide perspectives from students who are historically atrisk within the context of the WV educational system.

\section{LITERATURE REVIEW}

In post-secondary institutions of higher learning, the use of on-line or virtual platforms is prevalent (Lewis et al., 1997; Lewis et al., 1999; Waits and Lewis, 2003). According to a 2018 National Center for Education Statistics (NCES) report, approximately $35.5 \%$ of college students are in distance education courses with $16.6 \%$ exclusively attending on-line or virtual courses (NCES, 2019). The NCES disseminated a pre-COVID-19 national survey on distance-learning offerings in 2002-2003, and found that $36 \%(\mathrm{~N}=15,040)$ of school districts enrolled elementary and secondary school students in on-line learning platforms (NCES, n.d.). The study showed that larger school districts (50\%) enrolled more digital learners compared to medium-sized (32\%) and smaller school districts (37\%). Traditionally, administration of distance-learning courses for secondary school students is through a state virtual school. For postsecondary institutions, the delivery methods range from live or pre-recorded audio/ video to digital platforms (Camargo et al, 2020; NCES, n.d.). As the uncertainty of the pandemic loomed over the world, educational entities had to accept the inevitable - providing learning through virtual and/or remote platforms (Dziuban et al., 2018).

In October of 2020, HSTA's leadership started a conversation to examine the levels at which HSTA students struggled to learn during the pandemic. We acknowledge that as investigators on this research, we do not have roles in the school system. We are involved at various levels in the HSTA program as the program's director and evaluators. We are also community research associates, who are responsible for creating and implementing curriculum and content delivery. In order to conduct this study, we performed a search of survey instruments that addressed student learning during COVID-19 and found a viable source from the University of Wisconsin-Milwaukee (UWM) (University of Wisconsin, n.d.). Given the unprecedented nature of the pandemic, there were limited resources examining students' perspectives on how COVID-19 affected learning. Thus, the UMW survey was one of the first to query students about their educational experiences during these times. We created the Learning Outcomes survey by combining some questions taken from the UWM survey and HSTA key personnel.

\section{METHODS}

To understand whether a difference was present in satisfaction with learning and keeping up with school during 
the pandemic for participants (i.e., Yes, No, Somewhat) by enrollment in learning environments (e.g., Blended/Hybrid, In-Person, Virtual/On-line, etc.), a Pearson chi-square was conducted. We believe this is the optimal statistical procedure to use because we collected frequency data for the aforementioned variables. As such, chi-square analysis is the statistical procedure of choice when both variables are categorical. In addition, with the large sample size, expected counts per cell was usually more than five. Therefore, the assumptions for utilizing a chi-square are evident. When cell counts were not large enough, we collapsed categories (e.g. race) as well as performed Fisher's exact test of independence on variables with expected numbers less than 5 when applicable (McDonald, 2021).

After determining the types of questions on which to query HSTA students, we utilized the REDCap (Harris et al, 2009; Harris et al, 2019), HIPAA compliant database to create the survey. The survey questions included the following components: demographic information (e.g., race), educational environment (e.g., blended/hybrid), change environment, taking AP/Dual credit courses, satisfaction with learning and teacher availability, quality of HSTA programming, use of technology, confidence with learning, difficulty with learning/understanding subjects, how they learn best, who gives them encouragement to learn, and academic intentions after high school. For approximately three weeks in December 2020, HSTA students had the opportunity to complete the on-line survey with 418 students completing the survey. Of this number, 409 released their responses for research purposes. Participants could also respond to a few or all of the questions in the survey denoting differences in the total N's for each question. We present overall descriptive statistics of students' learning perceptions as well as categorized by the learning environments in which participants were enrolled at the time of survey completion relative to learning and technology.

We used the SPSS statistical software to perform the chisquare test of independence to test the dependence of the two categorical variables. Learning environments of HSTA students (nominal variable) relative to satisfaction with education and ability to keep up with school-work (ordinal variables) were examined. A p-value less than or equal to .05 led to rejecting the null hypothesis indicating that the independent variable affected the dependent variable. If the chi-square test indicated that the independent variable affected the dependent variable, then the Cramer $\mathrm{V}$ and Phi coefficient tests were calculated to show the strength of correlation between the variables ranging from 0 as no correlation to 1.0 as perfect correlation (Cohen, 1988). We used QDA Miner Lite, a free qualitative software sponsored by PROVALIS RESEARCH to code the qualitative data. (Provalis Research, 2020).

\section{RESULTS}

Descriptive Demographics. Approximately 53.8\% (N= 759) of current HSTA students completed the survey. The HSTA students to complete the survey $(\mathrm{N}=409)$ resided in 26 of the 55 West Virginia counties with Kanawha (13\%), Raleigh (11\%) and McDowell (8\%) county students having the majority representation, respectively. Other counties represented were Boone (7\%), Marshall and Mercer (5\%) and the remainder of the counties comprised $51 \%(\mathrm{~N}=401)$. Approximately $73 \%$ of the responders were female and $27 \%$ were male. Approximately $24 \%$ were 9 th and 10 th graders, $25 \%$ were 11 th graders and $26 \%$ were 12 th graders. Figure 1 shows responders' race/ethnicity.

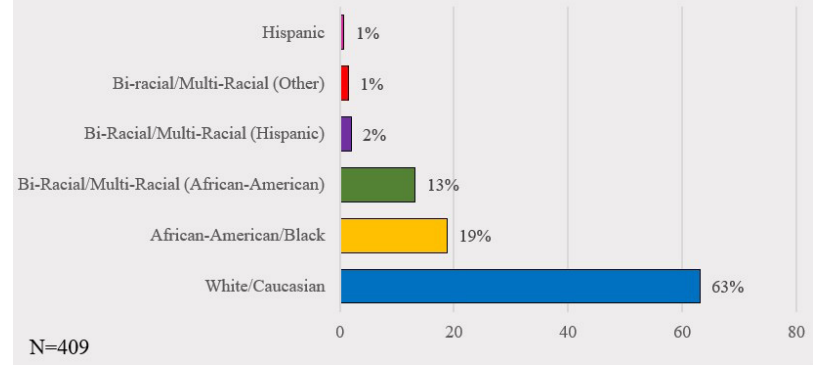

Figure 1. Responders' Race/Ethnicity

Learning Environment: Satisfaction with Learning, Keeping Up with School. HSTA participants were engaged in 5 types of learning environments when they completed the survey. The majority (42\%) were in the Blended or Hybrid (i.e. in person and virtual/on-line) environment. Approximately 28\% were In-Person, 19\% were Virtual/Online through their home county, and $11 \%$ were Virtual/On-line through the WVDE. There was also an "Other" category (e.g., enrolled in dual credit courses at a college), which was collapsed into the Virtual/On-line learning through WVDE category since there were fewer than five respondents. HSTA participants enrolled in advanced placement (AP) and dual credit (DC) courses were $61 \%$ and $26 \%$, respectively. Approximately $29 \%(\mathrm{~N}=407)$ and $13 \%(\mathrm{~N}=404)$ of Blended or Hybrid learners reported taking AP and DC courses. In comparison, of In-Person learners only $17 \%$ took AP and $8 \%$ took DC courses. Virtual/Online learners through their home county represented $11 \%$ (AP) and 3\% (DC) of the course takers. Finally, of the WVDE Virtual/Online learners, 5\% took AP and $2 \%$ took DC courses. We also queried participants on their preference of learning style as well as their levels of satisfaction with the education they have received since the pandemic. Approximately $72 \%$ preferred in-person learning with $17 \%$ preferring the blended/hybrid and $11 \%$ the virtual learning style.

This research focused on learning environments relative to satisfaction with learning and ability to keep up with school-work, teacher availability to help and teacher support 
in learning during the pandemic. Overall, 58\% indicated that they were "somewhat" satisfied with the education they have received since the COVID-19 pandemic. Approximately, 22\% indicated they were not satisfied and 20\% indicated they were satisfied with their education (Table 1). The chisquare test for learning environments and satisfaction level with education received was insignificant, $\chi 2(6, \mathrm{~N}=409)=$ $11.4, \mathrm{p}=.08$. The Fisher's exact test of independence was performed and found no relationship between satisfaction level with education and race (i.e., African American, Whites, Others), $\chi 2(4, \mathrm{~N}=409)=3.0 \mathrm{p}=.55$. Furthermore, the Pearson Chi-Square showed no relationship between gender and satisfaction level with education, $\chi 2(2, N=407)$ $=4.9 \mathrm{p}=.09$.

Overall, HSTA participants indicated they were keeping up with their school-work at various levels. Approximately $20 \%$ indicated a definite "Yes," and 58\% indicated they were "Somewhat" keeping up with their school-work. There were $22 \%$ who revealed they were not keeping up with their school-work. Table 1 provides a break-down by categories with chi-square results showing a significant difference in keeping up with school-work categorized by learning environments, $\chi 2(6, N=409)=15.3, p=.02$. The effect size for this finding, Phi, .19 and Cramer's V, .14 were small, so the differences have negligible practical significance (Cohen, 1988). Table 1 provides details of learners by educational environments. The Fisher's exact test of independence for race and keeping up with school-work showed no significant differences, $\chi 2(4, \mathrm{~N}=409)=3.0, \mathrm{p}=.56$. The Pearson Chi-Square for gender and keeping up with school-work also showed no relationship between the two variables $\chi^{2}(2$, $\mathrm{N}=407)=.43, \mathrm{p}=.81$.

Teacher Availability and Teacher Support in Learning. An important aspect of "keeping up with school-work" is teacher availability to help students with their work. This supports the learning process for students. Approximately $50.6 \%$ of HSTA students indicated that their teachers were available when they needed help with their learning. Furthermore, 56\% ( $\mathrm{N}=408)$ acknowledged that their teacher's feedback supports them across all platforms of learning, with $36.8 \%$ indicating that they are "somewhat" supported by their teacher's feedback when learning. The Fisher's exact test for learning environment and teacher availability to help showed a relationship between the variables, $\chi 2(6$, $\mathrm{N}=409)=12.3, \mathrm{p}=.04$. The effect size for this finding, Phi, .18 and Cramer's V, .13 were small, so the differences have negligible practical significance. Further analyses of teacher availability to help by race were insignificant, $\chi 2(4, N=408)$ $=1.5, \mathrm{p}=.80$, neither was there a relationship shown between teacher availability to help and gender, $\chi 2(2, N=407)=3.1$, $\mathrm{p}=.23$. When examining learning environment and teacher feedback supporting learning a relationship was shown
Table 1. Variables on Student Learning by Educational Environments.

\begin{tabular}{cccc}
\hline $\begin{array}{c}\text { Blended or } \\
\text { Hybrid Learning } \\
\text { (i.e., in-person } \\
\text { and virtual/ } \\
\text { online school } \\
\text { attendance) }\end{array}$ & $\begin{array}{c}\text { In-Person } \\
\text { Learning } \\
(\mathrm{N}=113)\end{array}$ & $\begin{array}{c}\text { Virtual/On- } \\
\text { line learning } \\
\text { through my } \\
\text { home county }\end{array}$ & $\begin{array}{c}\text { Virtual/On- } \\
\text { line through } \\
\text { the WV Dept. } \\
\text { of Education/ } \\
(\mathrm{N}=78)\end{array}$ \\
$\begin{array}{c}\text { Dual Credit } \\
\text { at Local Col- } \\
\text { lege }(\mathrm{N}=45)\end{array}$
\end{tabular}

Satisfaction with Education

\begin{tabular}{|c|c|c|c|c|}
\hline Yes & $16 \%$ & $22 \%$ & $23 \%$ & $27 \%$ \\
\hline Somewhat & $55 \%$ & $65 \%$ & $56 \%$ & $51 \%$ \\
\hline No & $28 \%$ & $13 \%$ & $21 \%$ & $22 \%$ \\
\hline \multicolumn{5}{|c|}{ Keeping up with School } \\
\hline Yes & $46 \%$ & $63 \%$ & $46 \%$ & $38 \%$ \\
\hline Somewhat & $30 \%$ & $24 \%$ & $29 \%$ & $44 \%$ \\
\hline No & $24 \%$ & $13 \%$ & $24 \%$ & $18 \%$ \\
\hline \multicolumn{5}{|c|}{ Teacher available to help } \\
\hline Yes & $45 \%$ & $62 \%$ & $46 \%$ & $53 \%$ \\
\hline Somewhat & $50 \%$ & $37 \%$ & $50 \%$ & $47 \%$ \\
\hline No & $5 \%$ & $1 \%$ & $4 \%$ & $0 \%$ \\
\hline \multicolumn{5}{|c|}{ Teachers'feedback help support home/remote/blended/in-person learning } \\
\hline Yes & $48 \%$ & $64 \%$ & $55 \%$ & $69 \%$ \\
\hline Somewhat & $43 \%$ & $35 \%$ & $35 \%$ & $29 \%$ \\
\hline No & $9 \%$ & $2 \%$ & $10 \%$ & $9 \%$ \\
\hline
\end{tabular}

between the variables $\chi 2(6, N=408)=15.5, \mathrm{p}=.02$; however, the effect size was negligible, Phi, .20 and Cramer's $\mathrm{V}$, .14. The Pearson chi-square showed no relationship between teacher feedback supporting learning and race, $\chi 2(4$, $\mathrm{N}=408)=4.0, \mathrm{p}=.40$ nor was there a relationship shown between teacher feedback supporting learning and gender, $\chi 2(6, \mathrm{~N}=406)=2.3, \mathrm{p}=.31$. Table 1 incorporates responses across learning platforms regarding teacher's availability to help and teacher's feedback supporting their learning.

When examining difficulties by learning environments and subjects, Table 2 provides distinctions. Cell sample sizes were inadequate to test for differences. Across all learning environments, when asked if they were having difficulties learning/understanding many indicated that they were having difficulty in at least one of the major subject areas (i.e., Math, Science, English, etc.). Overall, students are having "extreme" to "some" difficulties in Math (31\%), Science (25\%), English (16\%), History (15\%) and Foreign Language $(17 \%)$ classes. HSTA students are academically inclined and motivated to pursue STEM degrees/careers. However, in the midst of this pandemic, they are encountering challenges to learn in their regular classroom environments.

Use of and Access to Technology during COVID-19. We queried HSTA participants on their use of and access to technology during the COVID-19 pandemic. Many indicated that they have access to technology and internet services in order to attend on-line classes and/or complete their school-work (Figure 2). However, approximately $30 \%$ revealed that they had problems with using technology (e.g., computers, tab- 
Table 2. Percent of Level of Difficulty with Classes by Learning Environment.

\begin{tabular}{|c|c|c|c|c|}
\hline & $\begin{array}{l}\text { Blended or Hybrid } \\
\text { Learning (i.e., } \\
\text { in person and } \\
\text { virtual/online } \\
\text { school atten- } \\
\text { dance) }(\mathrm{N}=171)\end{array}$ & $\begin{array}{c}\text { In-Person } \\
\text { Learning } \\
(\mathrm{N}=110)\end{array}$ & $\begin{array}{c}\text { Virtual/ } \\
\text { Online } \\
\text { learning } \\
\text { through my } \\
\text { home county } \\
(\mathrm{N}=79)\end{array}$ & $\begin{array}{l}\text { Virtual/Online } \\
\text { through the } \\
\text { WV Dept. of } \\
\text { Education/Dual } \\
\text { Credit at Local } \\
\text { College ( } \mathrm{N}=43 \text { ) }\end{array}$ \\
\hline \multicolumn{5}{|c|}{ Math Class } \\
\hline $\mathrm{ED}$ & $8 \%$ & $6 \%$ & $10 \%$ & $7 \%$ \\
\hline $\mathrm{SD}$ & $22 \%$ & $19 \%$ & $26 \%$ & $30 \%$ \\
\hline $\mathrm{AD}$ & $30 \%$ & $26 \%$ & $23 \%$ & $34 \%$ \\
\hline ND & $39 \%$ & $48 \%$ & $41 \%$ & $30 \%$ \\
\hline \multicolumn{5}{|c|}{ Science Class } \\
\hline $\mathrm{ED}$ & $7 \%$ & $7 \%$ & $8 \%$ & $9 \%$ \\
\hline $\mathrm{SD}$ & $19 \%$ & $12 \%$ & $26 \%$ & $16 \%$ \\
\hline $\mathrm{AD}$ & $26 \%$ & $22 \%$ & $23 \%$ & $27 \%$ \\
\hline $\mathrm{ND}$ & $49 \%$ & $59 \%$ & $44 \%$ & $48 \%$ \\
\hline \multicolumn{5}{|c|}{ English Class } \\
\hline $\mathrm{ED}$ & $5 \%$ & $2 \%$ & $6 \%$ & $7 \%$ \\
\hline $\mathrm{SD}$ & $12 \%$ & $14 \%$ & $6 \%$ & $18 \%$ \\
\hline $\mathrm{AD}$ & $26 \%$ & $15 \%$ & $35 \%$ & $11 \%$ \\
\hline $\mathrm{ND}$ & $57 \%$ & $70 \%$ & $53 \%$ & $64 \%$ \\
\hline \multicolumn{5}{|c|}{ History Class } \\
\hline $\mathrm{ED}$ & $9 \%$ & $0 \%$ & $4 \%$ & $5 \%$ \\
\hline $\mathrm{SD}$ & $10 \%$ & $11 \%$ & $5 \%$ & $14 \%$ \\
\hline $\mathrm{AD}$ & $15 \%$ & $21 \%$ & $22 \%$ & $26 \%$ \\
\hline $\mathrm{ND}$ & $65 \%$ & $68 \%$ & $69 \%$ & $55 \%$ \\
\hline \multicolumn{5}{|c|}{ Foreign Language Class } \\
\hline $\mathrm{ED}$ & $7 \%$ & $7 \%$ & $10 \%$ & $14 \%$ \\
\hline SD & $8 \%$ & $9 \%$ & $7 \%$ & $12 \%$ \\
\hline $\mathrm{AD}$ & $14 \%$ & $8 \%$ & $17 \%$ & $5 \%$ \\
\hline ND & $71 \%$ & $76 \%$ & $66 \%$ & $69 \%$ \\
\hline
\end{tabular}

Note: I am having ( ) in this subject/class; $E D=$ Extreme Difficulty; $S D=$ Some Difficulty; $A D=A$ Little Difficulty; $N D=$ No Difficulties

lets, etc.) during class time or while doing assignments and homework. Participants also indicated the various levels at which their internet disconnected during class time (Figure $3)$. Of the 6 students that reported they did not have internet services at home, they either accessed internet through a mobile hotspot from their cell phone $(66.7 \%)$, mobile broadband or mi-fi (16.7\%) or used a mobile hotspot at a business $(16.7 \%)$.

Encouragement to Learn, Confidence in Learning, and Ways You Learn Best. We also asked HSTA students if they had received encouragement while learning during the semester. Approximately, 16.3\% indicated that they had not received encouragement. This question led to a series of questions related to their confidence in learning (Figures 4-7) and the levels of encouragement they received from parents, regular classroom and HSTA teachers, principals, guidance counselors, etc. Over 50\% indicated high levels of encouragement from their parents followed by their HSTA teachers (Table 3). Participants receive encouragement from

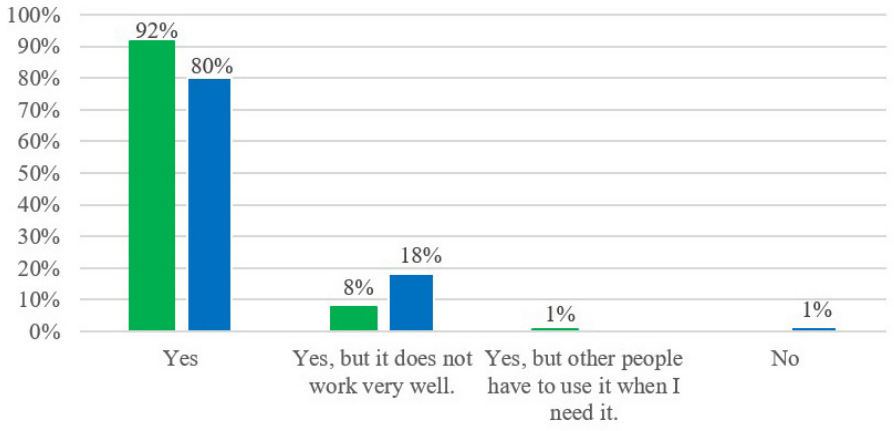

Do you have access to a computer or device (other than a smartphone) that you can use to attend your classes on-line and/or complete your school work? ( $N=409)$

- Do you have internet service at your home? $(\mathrm{N}=409)$

Figure 2. Responders' Access to a Computer or Device (Other than a Smartphone) and Internet Services.

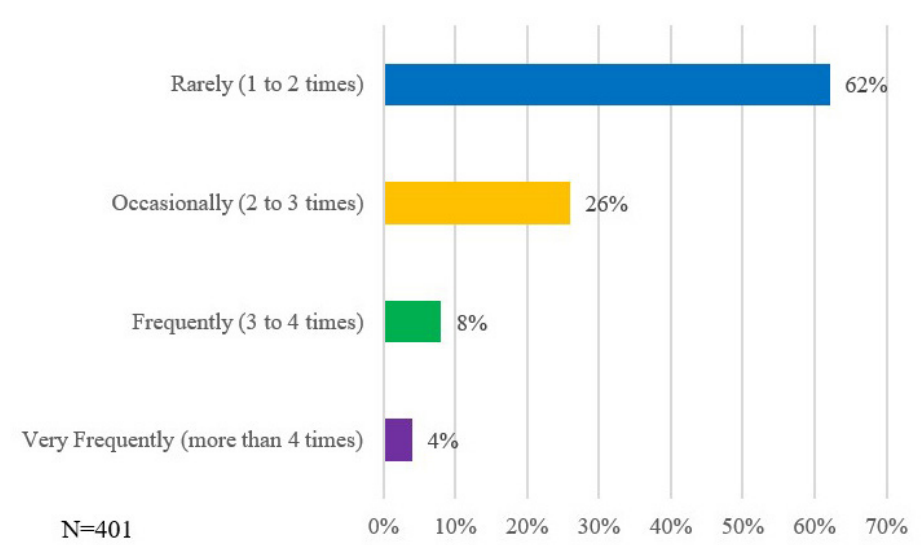

Figure 3. Frequency of Internet Disconnecting or Going 'On and Off' During Class Time.

HSTA teachers, who are also regular teachers in the school system, but are not necessarily participants' regular teacher during school hours. Field Site Coordinators are instrumental in guiding students through their HSTA experience by "checking" on them to make sure they are keeping up with their school-work so that they satisfy program requirements (Chester et al., 2020).

HSTA students were also asked to rank from 1st to 7 th the ways in which they learn best. Approximately 39\% indicated "listening to my teacher talk in front of the class" as the first way they learn best, which is indicative of the majority preferring the "in person" style of learning. Figure 8 provides a breakdown of the ways of learning. Students also indicated "hands-on projects or doing experiments," as a way they learned best with only a small percentage selecting the use of a computer or cell phone. Given the current situation, the data indicates that the pandemic has created a less than desirable learning environment.

Qualitative Responses. Participants provided approxi- 
Table 3. Responders' Level of Encouragement to Learn Received from the Following Individuals This Semester.

\begin{tabular}{|c|c|c|c|c|c|c|c|c|}
\hline & Parent(s) & $\begin{array}{l}\text { Legal Guardian(s) } \\
\text { or } \\
\text { Brothers/Sisters }\end{array}$ & $\begin{array}{l}\text { Regular } \\
\text { Classroom } \\
\text { Teachers }\end{array}$ & $\begin{array}{c}\text { HSTA } \\
\text { Teacher(s) }\end{array}$ & $\begin{array}{l}\text { Field Site } \\
\text { Coordinator }\end{array}$ & $\begin{array}{l}\text { Principal or } \\
\text { Guidance } \\
\text { Counselor }\end{array}$ & Friend(s) & From Yourself \\
\hline & $\mathrm{N}=409$ & $\mathrm{~N}=405$ & $\mathrm{~N}=407$ & $\mathrm{~N}=408$ & $\mathrm{~N}=399$ & $\mathrm{~N}=408$ & $\mathrm{~N}=408$ & $\mathrm{~N}=408$ \\
\hline No Encouragement & $3 \%$ & $12 \%$ & $5 \%$ & $3 \%$ & $15 \%$ & $17 \%$ & $12 \%$ & $9 \%$ \\
\hline Very Little Encouragement & $6 \%$ & $8 \%$ & $9 \%$ & $4 \%$ & $12 \%$ & $13 \%$ & $9 \%$ & $10 \%$ \\
\hline Some Encouragement & $12 \%$ & $19 \%$ & $25 \%$ & $18 \%$ & $24 \%$ & $23 \%$ & $19 \%$ & $20 \%$ \\
\hline Encouragement & $25 \%$ & $24 \%$ & $32 \%$ & $33 \%$ & $25 \%$ & $24 \%$ & $25 \%$ & $24 \%$ \\
\hline A Lot of Encouragement & $54 \%$ & $36 \%$ & $30 \%$ & $42 \%$ & $26 \%$ & $23 \%$ & $34 \%$ & $37 \%$ \\
\hline
\end{tabular}

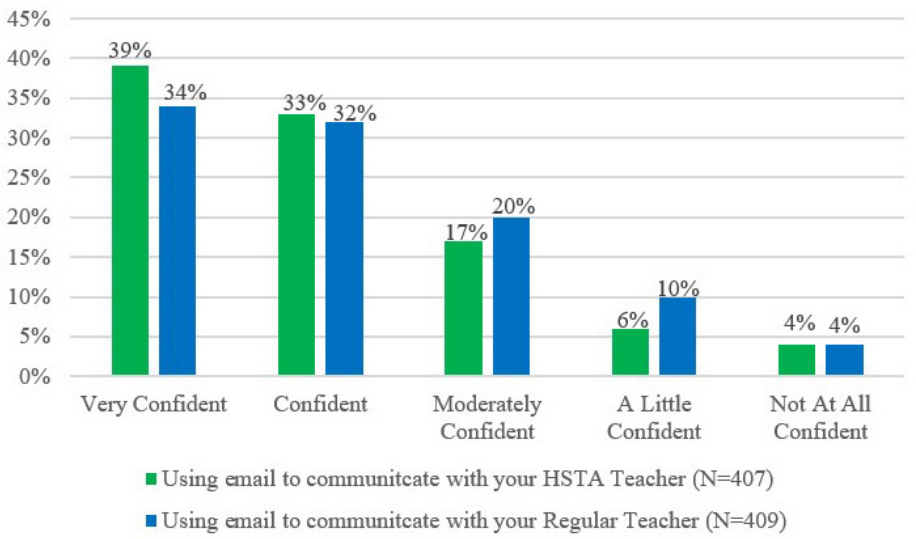

Figure 4. Responders' Levels of Confidence with Doing the Above Tasks.

mately 246 qualitative comments on how the school could improve on helping them to learn during the COVID-19 pandemic and over 230 comments on HSTA's program delivery. The key questions were "Please write any comments on how you believe HSTA can improve upon program delivery during COVID 19." and "Please write any comments on how you believe the school can improve on helping you to learn during COVID 19." As previously mentioned, we used the QDA Miner Lite software to code qualitative data.

HSTA's Program Delivery. Coding frequencies related to improving HSTA's program delivery revealed strong positive comments about the HSTA experience during COVID-19. Of the 239 comments coded on HSTA improvement, the dominant theme was that HSTA is doing a "great" job as shown in the following comment, "It's pretty organized, you guys do a great job." This key word appears $25.9 \%$ in the coded cases. As shown in Figure 9, some other highly coded key concepts included the following:

- $\quad$ No Suggestions * $20.1 \%$

- Assignments *14.6\%

- In Person-Meetings * $13.4 \%$

- Communication $* 9.6 \%$

- Good-Job *7.1\%

Note: $(*)$ denoting $\%$ appearance in the coded cases.

There were various comments categorized by the above

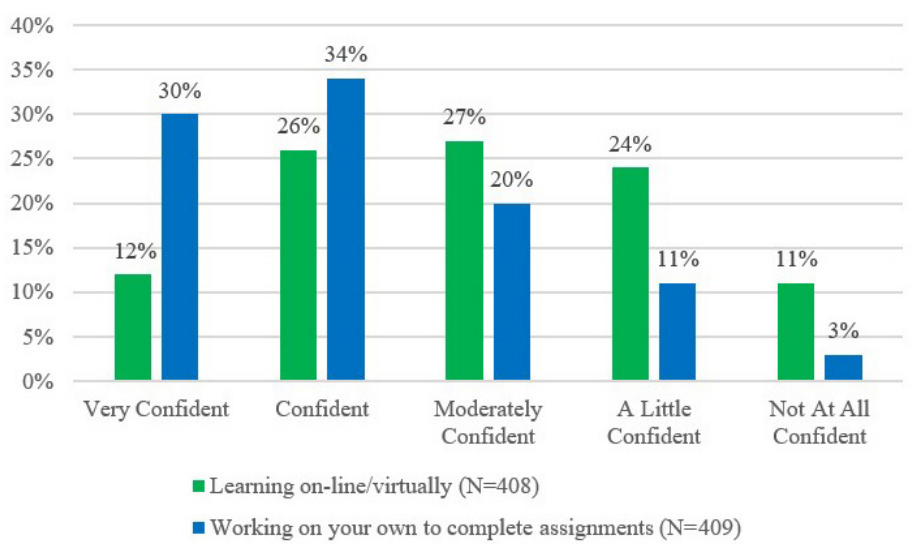

Figure 5. Responders' Levels of Confidence with Doing the Above Tasks.

codes. Participants believed that a key area for improvement were the virtual assignments as well as the need to relax program requirements.

"The homework assignments that we had to do that contained experiments were super fun, but the other assignments that were not experiments were dreadful and I did not enjoy them. It felt like busy work and I did not get much out of doing them."

"The community service expectation is currently unreasonable. In-person opportunities are a threat to the safety of the marginalized communities . . . and online opportunities are disproportionately unavailable to these marginalized communities due to reduced internet access (on top of the stresses and negative mental health impact of a global pandemic which disproportionately affects the low-income, Black/BIPOC, and rural students which this program serves). . this program should consider reworking their current expectations, perhaps on a case-by-case basis."

"It's hard for people who don't have good internet to work on everything so you can't expect the same from everyone and you still are and more if you expect everyone to have internet and can do everything you want us to do this year then you are wrong your 


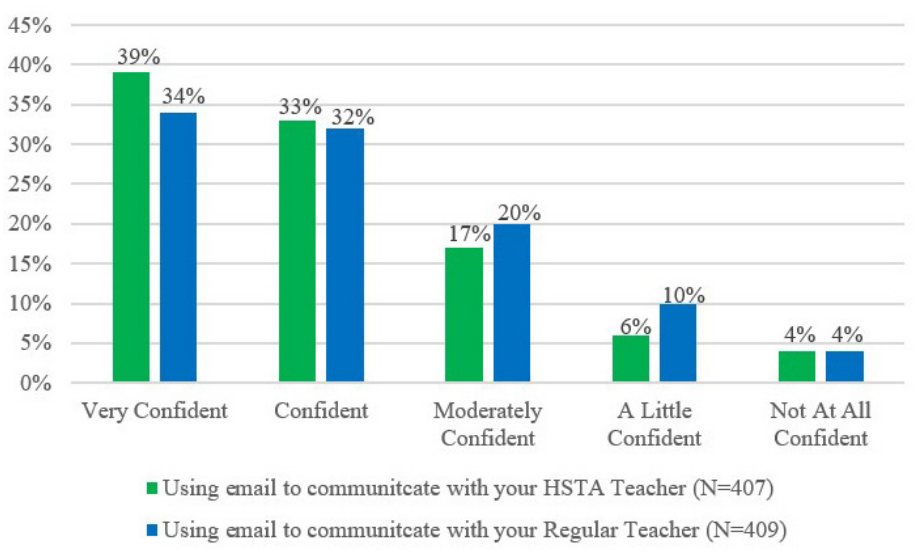

Figure 6. Responders' Levels of Confidence with Doing the Above Tasks.

(sic) punishing people for not being on a meeting that is wrong if you are going to expect that then you need to provide everything"

Another area of concern was communication between HSTA and participants with particular emphasis on due dates and connecting students to each other:

"Having a list of due dates for everything that HSTA requires us to comolete (sic) and events and community services can be put on the list too. It could also be a calendar instead, something easily accessible."

"HSTA can improve by allowing teachers to give more feedback on work given by packet."

"Finding ways to connect students from other clubs together so we can meet new people like we did before."

Conducting in-person meetings was a suggestion to improving program delivery:

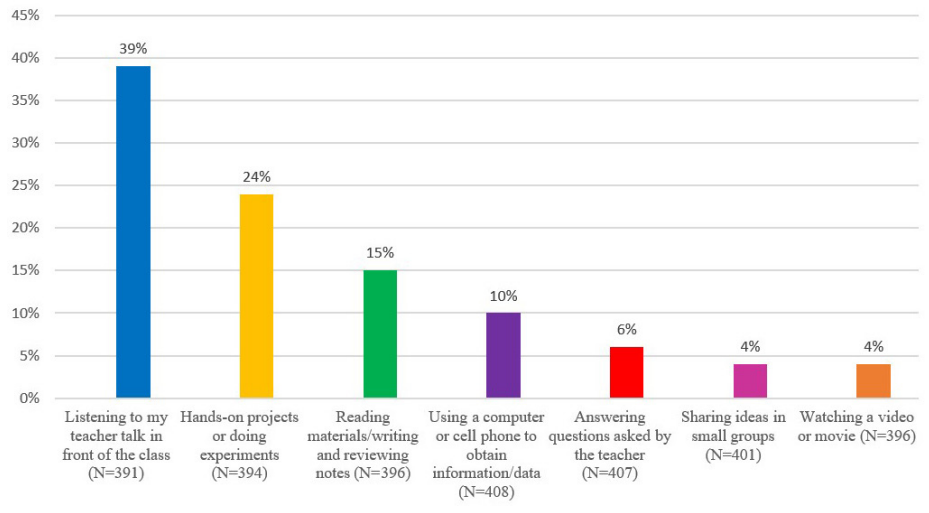

Figure 8. Responders' Ways in Which They Learn Best.

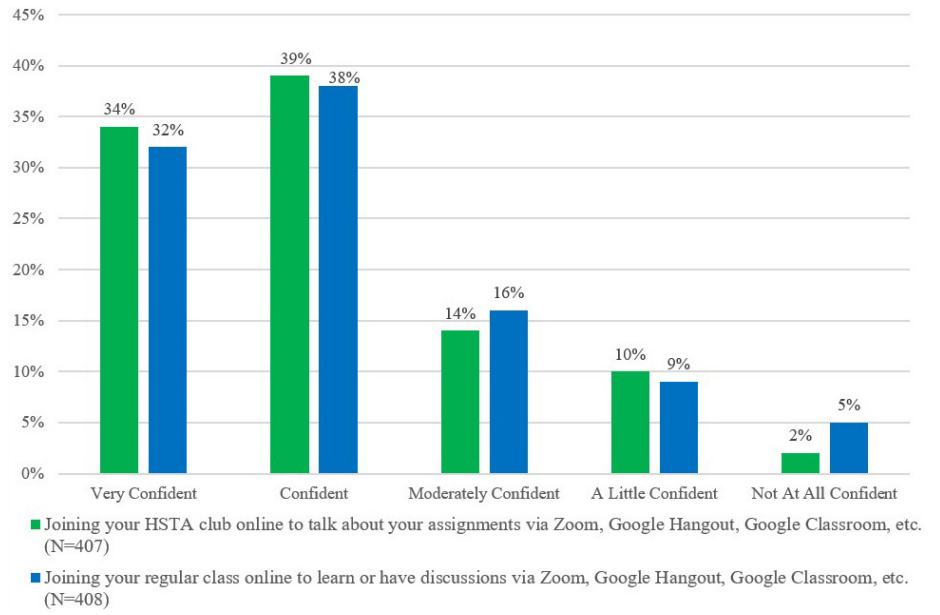

Figure 7. Responders' Levels of Confidence with Doing the Above Tasks.

"I believe HSTA should still construct the in person meetings because the experiments and experience is not the same. Constructing experiments at home is not beneficial to everyone. There of course should be limits, guidelines (sic) etc. but I think meetings should be in person."

Overall, there were numerous positive comments regarding HSTA's assistance in helping and providing them with support.

"I think HSTA is doing fine with their delivery, i like how organized things have been considering how chaotic the world is right now."

"I feel like HSTA has everything under control, and they have been insanely helpful during this hard time."

The School's Educational Delivery. The dominant theme regarding the schools' delivery of education was the heavy workload or extreme number of assignments as reflected in

\section{Great-Job}

Communication

\section{In Person-Meetings Meetingtimes-Lenient}

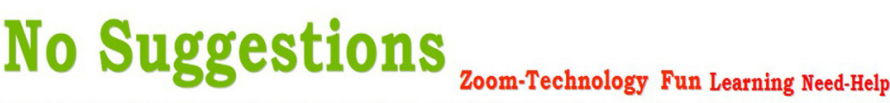
Help-Provided Incentives Community-Projects Guest-Speakers Information Be-Prepared Amazing

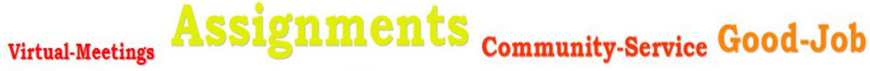
Doing-Best Limited-Internet Experiments Record-Meetings Not-the-Same Organized More-Organization

Figure 9. Word Cloud of Qualitative Comments on Improving HSTA Programming. 
the following statement: "The school could help improve my learning by not assigning the amount of work they have been assigning. I work around 13-14 hours a day on assignments and I am still falling behind." This key concept appears $22.8 \%$ in the coded cases. Figure 10 is a Word Cloud highlighting coded key concepts with higher frequency concepts shown below:

- Need-Help-Learning/Struggling-Or-Not-Learning * $19.10 \%$

- Be-Attentive/Answer-Messages/Interact-More * $15.0 \%$

- No Comments-Suggestions * $12.6 \%$

- In-Person Learning *8.9\%

- Zoom-Meetings-for-Learning/Need-Better-LearningSystem *6.1\%

Note: $(*)$ denoting $\%$ appearance in the coded cases.

Following the extreme workload concept, participants revealed that they were not learning, struggling with learning or needed help learning:

"It's easier for me to have my actual teachers teach me other than trying to teach myself"

"There is no teaching you are given the material and you are expected to comprehend it on your own basically."

"I feel like they should give us more time to complete our work. It doesn't really feel like I'm learning, just submitting before 12:00."

Some students had rather strong opinions about the schools' need to be attentive to the needs of the students, particularly those from underprivileged backgrounds. This is reflected in the comment below:

Our schools should opt to deliver more flexibility to their students. The number of teachers and administrators who've dismissed struggling students as "lazy" or refused to accept late work from students with unstable internet access is appalling. Not to mention the difficulties faced by students with mental health issues and/or disabilities; they've largely been relegated to the wayside and are not getting the care and accommodations which they require from their schools. At the moment, it seems as if only the most privileged students (i.e. those who are financially stable/upper-class and not facing the current economic turmoil, those who are able-bodied and mentally stable, and those largely unaffected by the political/racial unrest and uncertainty in this country; essentially those who can (1) afford a stable internet connection and (2) afford to focus physical

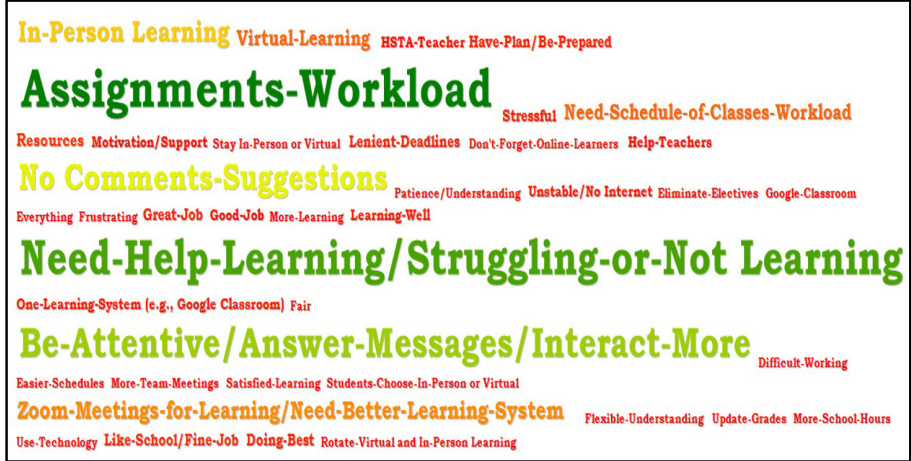

Figure 10. Word Cloud of Qualitative Comments on Improving Schools.

and mental energy on anything other than survival) are the only ones getting an education.

Other students revealed that in-person learning was the best option for them.

"The thing that I'm struggling with is the harder classes and only being there 2 days a week. The online lectures aren 't as good as learning it in person."

"The only way to improve the quality of my education is to go to full five-day school weeks..."

Finally, HSTA participants had concerns about the educational platforms used for learning and disseminating information, with specific mention of schoology, blackboard and edmentum learning systems. Students preferred google classroom and zoom meetings for educational delivery.

Since one of the program's primary goals is to assist students in achieving their academic goal of going to college, we asked participants to provide comments about their learning or their plans to go to college after high school during the COVID-19 pandemic. These reflections provided insight into the students' psychological state of being during this pandemic. Although there is a sense of fear as reflected by this participant,

Because of COVID-19 and its impact on my family, my future, and my mental state, I am the most uncertain I've ever been about even completing high school, let alone the HSTA program or potential college enrollment. I was on track to graduate until the pandemic hit, and now I feel I'm in a hole I cannot recover from and our administration is unwilling to extend accommodations for.

There is also a glimmer of hope with some expressing grit and determination:

"I plan to proceed in my medical career no matter the status of the pandemic. This pandemic is a per- 
fect example of the uncertainty of life so I am not going to allow a pandemic in my field to stop me from pursuing my dream career."

"I plan to work hard and push myself to get good grades in order to be able to go to college after I graduate."

Through the qualitative comments, students have the opportunity to voice their concerns and as a result; HSTA can reach out to students, such as the aforementioned, to assure them that we are supporting them in every way possible. Oftentimes, Field Site Coordinators perform an important role in helping and encouraging students to complete program requirements so that they can achieve their goal of attending college.

\section{DISCUSSION AND CONCLUSION}

This descriptive study provides a unique glimpse into the perspective of a subsection of the U.S. high school student population during the COVID-19 pandemic - those who are educationally motivated and driven to succeed but possibly lacking the resources to pursue post-secondary degrees. HSTA recognizes the importance of addressing the racial and social barriers that exist for at-risk student populations of West Virginia and believes that if underserved high school students have the potential and the desire to pursue a college degree and a health professions/STEM career, with support, they can reach their goals. Yet, in the midst of the educational crisis created by the pandemic, there is the possibility of derailed potential and desire due to the loss of learning.

As underserved and at-risk students with a majority living in rural areas, participants revealed that their learning has indeed suffered due to the pandemic as evidenced by their perspectives presented in this study. Overall, the majority affirm that they are somewhat or not at all keeping up with their school-work. Chi-square analysis revealed that the Virtual Learners taking classes through the WVDE were having more difficulty keeping up with their school-work; however, the correlation between these variables was not strong based on the Phi and Cramer V values. This weak correlation can be due to the "somewhat" category in which respondents were unsure in their responses. Nevertheless, Phi and Cramer's V showed almost no relationship between the variables. Thus, we cannot say that one type of learning environment was tolerable over another type. As a point of conjecture, participants acknowledged the difficulties associated with toggling between in-person and hybrid/blended learning.

Qualitative data revealed they were having difficulties learning due to several issues (i.e., more assignments, strict due dates, needing one-on-one help to learn concepts, in- efficiencies of the blended/hybrid model, etc.) However, since we conducted this entire study during the pandemic, we acknowledge that we do not know if participants' opinions would be the same or different, if they were entirely in the in-person learning environment. Nevertheless, it seems that students favored in-person learning because they received direct instruction from the teachers, and did not have to "teach" themselves, but many understood the importance of heeding safety protocols. Given that $10 \%$ or less of HSTA students, in either learning environment, indicated that the teachers were not available to help them or that teacher feedback did not support their learning is an indication that they did not perceive the teachers as inhibiting their learning. For HSTA students, HSTA teachers are an important source of encouragement for inspiring them to learn with $75 \%$ indicating they received "Encouragement" or "A Lot of Encouragement." This is critical for underrepresented students in mitigating loss as well as maintaining and increasing learning gains.

In conjunction with educational losses are psychological losses for at risk students (Thakur, 2020). Golberstein et al. (2020) purport that mental health problems may increase among children and adolescents due to "the unique combination of the public health crisis, social isolation, and economic recession." In a response to the aforementioned brief, Poletti and Raballo (2021) note that lower socioeconomic families have fewer resources (e.g., internet access, dedicated homework spaces, etc.) so that these students can have difficulty mitigating learning loss. According to a recent study of Chinese middle and high school students $(\mathrm{N}=1,025)$, over one fifth of these students' mental health suffered during COVID-19 (Zhang et al., 2020). We are just at the tip of the iceberg in understanding the learning and psychological costs of this pandemic.

The psychological impact on HSTA participants has welded multifaceted responses ranging from fear and uncertainty to hope and determination. Despite all of the difficulties encountered, there was nevertheless a perseverance to continue to strive and achieve, which may be due to their goal orientation and HSTA program structure as exhibited in the qualitative results. We believe that this study provides a glimpse of what underprivileged, at-risk, and rural students were/are going through that might have use both nationally and in rural environments. It is important to note that despite their exceptional drive to achieve, some HSTA participants lack the resources or incentives to go to college and beyond; as a result, they are more inclined to suffer from educational fallout due to the pandemic (Agostinelli et al. and National Bureau of Economic Research, 2020; Rothstein, 2020).

We have also collected a second round of data in order to perform comparative analysis of December 2020 to April 2021. In April of 2021, the majority of students were attending school in-person for 5 days a week; thus to see if there 
were any changes would be helpful in further understanding their perspectives. This study has allowed HSTA to understand the difficulties participants encountered while learning during the pandemic. These results have also provided viable information for the leadership and staff to create a more effective virtual learning environment during the Summer of 2021. Furthermore, this information could potentially inform educators on student perspectives of learning the pandemic. This study could also assist teachers and educational administrators in understanding the learning pitfalls students might have encountered as well as the support mechanisms they needed to help them persist through the educational pipeline during the COVID-19 pandemic.

\section{AUTHOR INFORMATION Corresponding Author}

Sherron McKendall.smckendall@hsc.wvu.edu

\section{Author Contributions}

The manuscript was written through contributions of all authors. All authors have given approval to the final version of the manuscript.

\section{ACKNOWLEDGMENTS}

The authors would like to acknowledge the strong support and dedication of the HSTA Joint Governing Board and Local Governing Boards throughout the state of WV. We also acknowledge the many wonderful teachers and staff who have dedicated their skills and time to making opportunities for deserving students who are underserved in educational communities. We also want to recognize all the legislators over the history of HSTA who have supported and maintained the level of funding needed to sustain HSTA for all these years.

\section{FUNDING SOURCES}

Funding was provided through NIH NIGMS-Science Education Partnership Award R25OD023768, NSF award OIA1920920, and support from the West Virginia Legislature.

\section{ABBREVIATIONS}

AP: Advanced Placement; COVID-19: SARS-CoV-19; DC: Dual Credit; DHHR: Department of Health and Human Resources; HSTA: Health Sciences and Technology Academy; OST: Out-of-School-Time; UWM: University of Wisconsin-Milwaukee; WV: West Virginia; WVDE: West Virginia Department of Education

\section{REFERENCES}

ACT. (2018). The Condition of College and Career Readiness 2018. http:/www.act.org/content/dam/act/unsecured/documents/cccr2018/National-CCCR-2018.pdf

Agostinelli, F., Doepke, M., Sorrenti, G., Zilibotti, F., and National Bureau of Economic Research. (2020). When the great equalizer shuts down: schools, peers, and parents in pandemic times (Ser. Nber working paper series, no. 28264). National Bureau of Economic Research.

Anderson, M., and Perrin, A. (2018, October 26). Nearly one-infive teens can't always finish their homework because of the digital divide. Retrieved March 24, 2021, from https:// www.pewresearch.org/fact-tank/2018/10/26/nearly-onein-five-teens-cant-always-finish-their-homework-becauseof-the-digital-divide/

Arias, J. J., Swinton, J., and Anderson, K. (2018) Online vs. Faceto-Face: A comparison of student outcomes with random assignment. e-Journal of Business Education and Scholarship of Teaching, 12(2), 1-23. Retrieved April 6, 2021 from https://files.eric.ed.gov/fulltext/EJ1193426.pdf

Camargo, C., Tempski, P., Busnardo, F., Martins, M., and Gemperli, R. (2020, November 6). Online learning and covid-19: A Meta-synthesis analysis. Retrieved March 16, 2021, from https://www.ncbi.nlm.nih.gov/pmc/articles/ PMC7605278/.

Chen, L., Dorn, E., Sarakatsannis, J., and Wiesinger, A. (2021, March 12). Teacher survey: Learning loss is global--and significant. Retrieved March 24, 2021, from https://www. mckinsey.com/industries/public-and-social-sector/our-insights/teacher-survey-learning-loss-is-global-and-significant

Chester, A., McKendall, S., McKendall, A., Mann, M., Kristjansson, A., Branch, R., Hornbeck, B., Morton, C., Kuhn, S., Smith Branch, F., and Barnes-Rowland, C. (2020, October 21). The Health Sciences and Technology Academy (HSTA): Providing 26 years of academic and social support to Appalachian youth in West Virginia. Journal of STEM Outreach. Retrieved October 27, 2020, from https://www.jstemoutreach.org/article/17703-the-healthsciences-and-technology-academy-hsta-providing-26years-of-academic-and-social-support-to-appalachianyouth-in-west-virginia.

Cohen, J. (1988). Statistical power analysis for the behavioral sciences (2 ed.). Hillsdale, NJ: Lawrence Erlbaum Associates.

Coleman, J. S., Campbell E. Q., Hobson C. J., McPartland J., Mood, A. M., Weinfeld, F. D., and York, R. L. 1966. Equality of Educational Opportunity. Washington, DC: U.S. Government Printing Office.

Dorn, E., Hancock, B., Sarakatsannis, J., and Viruleg, E. (2021, March 01). COVID-19 and learning loss--disparities grow and students need help. Retrieved March 24, 2021, from https://www.mckinsey.com/industries/public-and-social-sector/our-insights/covid-19-and-learning-loss-disparities-grow-and-students-need-help. 
Dziuban, C., Graham, C.R., Moskal, P.D., Norberg, A., and Sicilia, N. (2018). Blended learning: the new normal and emerging technologies. International Journal of Education Technology in Higher Education. 15, 3. https://doi.org/10.1186/ s41239-017-0087-5.

Engzell, P., Frey, A., and Verhagen, M. (2021, April 27). Learning loss due to school closures during the COVID-19 pandemic. Retrieved April 15, 2021, from https://www.pnas.org/ content/118/17/e2022376118.

Golberstein, E., Wen, H., and Miller, B. (2020, September 01). COVID-19 and mental health for children and adolescents. Retrieved March 24, 2021, from https://jamanetwork.com/ journals/jamapediatrics/fullarticle/2764730.

Hanushek, E. A., and Woessmann, L. (2020, September). The Economic Impacts of Learning Losses. Retrieved April 15, 2021, from https://www.oecd.org/education/The-economic-impacts-of-coronavirus-covid-19-learning-losses.pdf.

Harris, P.A., Taylor, R., Thielke, R., Payne, J.,Gonzalez, N., and Conde, J.G. (2009, April). Research electronic data capture (REDCap) - A metadata-driven methodology and workflow process for providing translational research informatics support. Journal of Biomedical Informatics, 42(2), 377-81.

Harris, P.A., Taylor, R., Minor, B.L., Elliott, V., Fernandez, M., O’Neal, L., McLeod, L., Delacqua, G., Delacqua, F., Kirby, J., and Duda, S.N. (2019). The REDCap consortium: Building an international community of software partners. Journal of Biomedical Informatics, May 9 [doi: 10.1016/j. jbi.2019.103208]

Kuhfeld, M., Soland, J., Tarasawa, B., Johnson, A., Ruzek, E., and Liu, J. (2020). Projecting the potential impact of covid-19 school closures on academic achievement. Educational Researcher, 49(8), 549-565. doi:10.3102/0013189x20965918.

Li, C., and Lalani, F. (2020, April 29). The COVID-19 pandemic has changed education FOREVER. This is how. Retrieved March 16, 2021, from https://www.weforum.org/agenda/2020/04/coronavirus-education-global-covid19-online-digital-learning/.

Lewis, L., Alexander, D., and Farris, E. (1997). Distance Education in Higher Education Institutions (NCES 98-062). U.S. Department of Education. Washington, DC: National Center for Education Statistics.

Lewis, L., Snow, K., Farris, E., and Levin, D. (1999). Distance Education at Postsecondary Education Institutions: 1997-98 (NCES 2000-013). U.S. Department of Education. Washington, DC: National Center for Education Statistics.

McDonald, J. H. (2021, May 1). 2.8: Small Numbers in Chi-Square and G-Tests. Statistics LibreTexts. https://stats.libretexts. org/Bookshelves/Applied Statistics/Book\%3A Biological Statistics (McDonald) $/ 02 \% 3 \mathrm{~A}$ Tests for Nominal Variables/2.08\%3A_Small_Numbers_in_Chi-Square_and_GTests.
McKendall, S. B., McKendall, A., and Chester, A. (2019). A comparison of academic performance measures of HSTA participants with non-HSTA participants: Is it possible to narrow the African American-White achievement gap? Journal of STEM Outreach, 2(1), 1-10.

McKendall, S. B., McKendall, A., Kuhn, S., Morton, C., and Freeland, S. (2021). The Health Sciences and Technology Academy: Re-imagining programmatic delivery during the COVID pandemic. Manuscript submitted for publication.

Means, B. (2009). Evaluation of evidence-based practices in online learning: A meta-analysis and review of online learning studies. U.S. Department of Education, Office of Planning, Evaluation and Policy Development, Policy and Program Studies Service.

National Center for Education Statistics. (n.d.). Distance education courses for public elementary and secondary school Students: 2002-03. Retrieved March 15, 2021, from https:// nces.ed.gov/surveys/frss/publications/2005010/.

National Center for Education Statistics. (2019). Fast Facts Distance learning. U.S. Department of Education. Retrieved March 15, 2021, from https://nces.ed.gov/fastfacts/display.asp?id=80.

Office of the Governor Jim Justice. (2020, August 05). COVID-19 UPDATE: Gov. Justice announces reopening plan for West Virginia schools. Retrieved March 23, 2021, from https://governor.wv.gov/News/press-releases/2020/Pages/ COVID-19-UPDATE-Gov.-Justice-announces-reopeningplan-for-West-Virginia-schools.aspx

Paul, J., and Jefferson, F. (2019, October 15). A comparative analysis of student performance in an online VS. Face-to-Face environmental science course from 2009 to 2016. Retrieved April 06, 2021, from https://www.frontiersin.org/ articles/10.3389/fcomp.2019.00007/full.

Perrin, A. (2019) Digital gap between rural and nonrural America persists. Accessed June 20, 2020. https://www.pewresearch.org/fact-tank/2019/05/31/digital-gap-between-rural-and-nonrural-america-persists/.

Poletti, M., and Raballo, A. (2021). Coronavirus disease 2019 and effects of school closure for children and their families. JAMA Pediatrics, 175(2), 210. doi:10.1001/jamapediatrics. 2020.3586

Oppenheimer, T. (2003). The flickering mind: The false promise of technology in the classroom, and how learning can be saved (1st ed.). Random House.

Provalis Research. (2020, November 29). Free Qualitative Data Analysis Software: QDA Miner Lite. https://provalisresearch.com/products/qualitative-data-analysis-software/ freeware/. 
Reimers, F., Schleicher, A., Saavedra, J., and Tuominen, S. (2020). Supporting the continuation of teaching and learning during the COVID-19 Pandemic. Annotated resources for online learning. Retrieved April 15, 2021, from https:// www.oecd.org/education/Supporting-the-continuation-ofteaching-and-learning-during-the-COVID-19-pandemic. pdf.

Rothstein, R. (2020, April 14). The coronavirus will explode achievement gaps in education. Retrieved April 06, 2021, from https://www.epi.org/blog/the-coronavirus-will-explode-achievement-gaps-in-education/.

Smith, F., McKendall, S., Chester, A., Hornbeck, B., and McKendall, A. (2018). Demonstrating the efficacy of the Health Sciences and Technology Academy: Using archival standardized test scores to analyze an OST college-preparatory program for underserved youth, Journal of STEM Outreach, 1, 1-11.

Thakur, A. (2020, December). Mental health in high school students at the time of covid-19: A student's perspective. Retrieved March 24, 2021, from https://www.ncbi.nlm.nih. gov/pmc/articles/PMC7448765/

Tilson, and The West Virginia Broadband Enhancement Council. (2019, December 5). West Virginia State Broadband Plan: Approved for Public Comment. Retrieved April 13, 2021, from https://broadband.wv.gov/wp-content/ uploads/2019/12/West_Virginia_State_Broadband_ Plan_2020-2025_Public_Comment-Draft.pdf

University of Wisconsin Milwaukee (n.d.). Wisconsin Home/Remote Learning Survey. Retrieved March 12, 2021, from https://milwaukee.qualtrics.com/jfe/form/SV_aarZcmZqJippU57

Waits, T., and Lewis, L. (2003). Distance Education at degree-granting postsecondary institutions: 2000-2001(NCES 2003017). Washington, DC: U.S. Department of Education, National Center for Education Statistics.

West Virginia Department of Education (WVDE). (2021, March 01). School recovery protocols. Retrieved March 18, 2021, from https://wvde.us/school-recovery-protocols/

West Virginia Department of Education (WVDE). (2021, March 10). COVID recovery timeline. Retrieved March 18, 2021, from https://wvde.us/covidtimeline/\#februarylist

West Virginia Department of Education (WVDE). (n.d.). Instructional Options-Strengths Considerations. Retrieved March 20, 2021, from https://wvde.us/wp-content/uploads/2021/01/InstructionalOptions-StrenthsConsiderations.pdf

WSAZ News Channel 3. (2020, August 5). W.Va. gov. justice announces program to ensure internet access for students. Retrieved March 23, 2021, from https://www.wsaz. com/2020/08/06/wva-gov-justice-announces-program-toensure-internet-access-for-students/

WV kids connect initiative. (2020, October 13). Retrieved March 23, 2021, from https://wvkidsconnect.net/.
Young, C. (2020, September08). West Virginia Gov.JUSTICE: More than 800 KIDS connect SITES complete. Retrieved March 23, 2021, from https://www.wvnews.com/news/wvnews/ west-virginia-gov-justice-more-than-800-kids-connectsites-complete/article_81297a83-8979-51ff-ae34-fded9fb51c90.html.

Zhang, C., Ye, M., Fu, Y., Yang, M., Luo, F., Yuan, J., and Tao, Q. (2020, December). The psychological impact of the Covid-19 pandemic on teenagers in China. Retrieved March 24, 2021, from https://www.ncbi.nlm.nih.gov/pmc/ articles/PMC7543885/ 